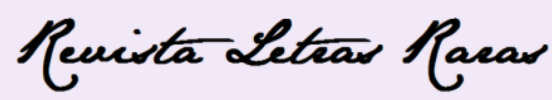

ISSN: 2317-2347 - Vol. 5, Ano 5, № 1 - 2016

\title{
Imagem e texto: \\ A intertextualidade na educação de surdos
}

\author{
Elaine Cristina Paixão* \\ Cássia Geciauskas Sofiato*
}

\begin{abstract}
Resumo: O ensino da leitura e da escrita para alunos surdos é um trabalho desafiador em virtude das especificidades que se colocam no processo de aquisição da língua de sinais e da língua portuguesa. Dentro de uma perspectiva de educação bilíngue, o trabalho com a intertextualidade, por meio do diálogo entre imagem e texto escrito, pode favorecer o desenvolvimento dos alunos surdos. Este trabalho objetiva contribuir com a reflexão sobre a importância do uso da imagem e do texto para a aquisição da leitura e escrita de alunos surdos. Trata-se de uma pesquisa qualitativa e de cunho bibliográfico. Como fontes foram utilizados artigos científicos e livros que abordam a questão. Com base nos estudos realizados observa-se que o trabalho com a intertextualidade, envolvendo a imagem, o texto escrito e também a língua de sinais, além de ser importante para o desenvolvimento de linguagem ainda pode colaborar para a aprendizagem da leitura, da escrita e desenvolvimento do processo de letramento com alunos surdos.
\end{abstract}

Palavras-chave: Letramento. Imagem. Educação de surdos

\section{USING IMAGE AND TEXT : INTERTEXTUALITY IN THE EDUCATION OF DEAF STUDENTS}

\begin{abstract}
Teaching deaf students how to read and write is a challenging task due to the specific needs added to the process of both sign and Portuguese language acquisition. Within an educational perspective bilingual, working with intertextuality, through the dialogue between image and written text, may be favorable to the development of deaf students. This study aims to contribute with the reflection on the importance of using image and text to teach deaf students how to read and write. This is a qualitative research with bibliographic basis, having scientific articles and books as sources. Based on the researched studies, it is possible to observe that the use of intertextuality, involving image, written text and sign language as well as being important for the development of language can also contribute to the learning of reading, writing and literacy development process with deaf students.
\end{abstract}

Keywords: Literacy. Image. Deaf education.

\section{Introdução}

O ensino da leitura e da escrita para alunos surdos tem sido pesquisado por muitos estudiosos devido às suas especificidades e desafios. A abordagem bilíngue, na educação de

\footnotetext{
* Professora, fonoaudióloga, especialistas em educação especial para alunos com deficiência intelectual e auditiva, mestranda em educação pela Universidade de São Paulo, fonoaudióloga da Secretaria de Educação do município de São Bernardo do Campo. E-mail: elainepaixao.in@gmail.com. tel. (11) 41247283 ou (11) 993061519.

* Pedagoga, especialista em Educação Especial. Mestre e doutora em Artes pela Universidade Estadual de Campinas. Docente da Faculdade de Educação e Programa de Pós-graduação da Universidade de São Paulo. Email: cassiasofiato@usp.br.
} 


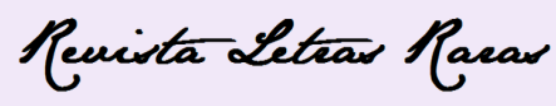

ISSN: 2317-2347 - Vol. 5, Ano 5, № 1 - 2016

surdos, considera que a primeira língua a ser adquirida pela criança surda é a língua de sinais (no Brasil denominada Libras) e a segunda é a língua do país (no caso do Brasil, língua portuguesa, na modalidade escrita). Assim sendo, a aprendizagem da leitura e da escrita não é uma tarefa simples, pois, além das diferentes características das línguas mencionadas, ambas possuem modalidades distintas: a Libras é espaço-visual e a língua portuguesa, oral-auditiva (FERNANDES, 2006).

Um fato que também interfere neste processo é que muitos alunos surdos adquirem tardiamente a Libras, pois a maioria tem pais ouvintes que não sabem tal língua. Isso incide significativamente na aquisição da língua de sinais e consequentemente na aquisição de outras línguas. Associa-se a estas questões que permeiam a educação de surdos, o desafio nacional referente ao ensino da leitura e da escrita para todos os brasileiros e o entendimento da natureza da leitura e da escrita como um ato político, social, intelectual e linguístico (KARNOPP, 2002).

No caso de alunos surdos, a questão também toma outra dimensão, pois segundo Karnopp; Pereira (2012):

As práticas pedagógicas pouco exploram a capacidade linguística do aluno surdo, pressupondo ser ele uma tábula rasa, um estranho em relação ao português, alguém que precisa e depende integralmente do professor, do ouvinte para extrair o significado de um texto. A aprendizagem da leitura e da escrita é vista não como um processo ativo, mas meramente receptivo, de dependência do outro. Nesse sentido, observamos, constantemente, adaptações de textos originais por parte do professor antes de fornecê-lo ao aluno ou textos infantilizados, inadequados aos interesses e à idade dos alunos (p. 131).

Observa-se que a tarefa de e desenvolver o letramento visual com alunos surdos é desafiadora e tem levado alguns autores, tais como: Gesueli (2003), Karnopp; Pereira (2012), Goés (2002), Lodi (2006), entre outros, a dedicar-se profundamente a essas questões. Além disso, há outra gama de autores que têm se dedicado ao estudo do uso de recursos visuais no processo de ensino a alunos surdos: Reily (2003, 2004), Sofiato; Reily (2013), Taveira; Rosado (2013), Rosa; Luchi (2010), Lebedeff (2010), entre outros. A imagem é um dos recursos comumente mais estudados e utilizados nas práticas pedagógicas com os referidos alunos.

Nesse sentido, o Decreto-Lei $\mathrm{n}^{\circ} 5626$ de 2005, corrobora com esta iniciativa, ao destacar no capítulo um, artigo $2^{\circ}$, a seguinte definição de pessoa surda: “considera-se pessoa 


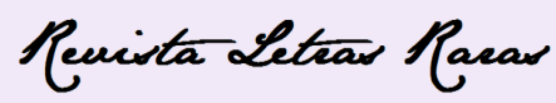

ISSN: 2317-2347 - Vol. 5, Ano 5, № 1 - 2016

surda aquela que, por ter perda auditiva, compreende e interage com o mundo por meio de experiências visuais, manifestando sua cultura principalmente pelo uso da Língua Brasileira de Sinais - Libras" (BRASIL, 2005). Considerando este aspecto e entendendo a leitura de forma mais ampla e não mera decodificação de símbolos gráficos, a leitura de imagem vem ganhando um lugar de destaque na educação de surdos.

O trabalho com a intertextualidade, neste caso contemplando o texto escrito e a imagem, pode favorecer a aprendizagem da leitura com compreensão para todos os alunos e especialmente para alunos surdos. De acordo com Cavalcante (2009) não há um consenso nos estudos linguísticos e literários a respeito do conceito de intertextualidade. Assim sendo, não se trata de noção teórica consensual e pontual nos estudos da linguagem.

Hall (2008) discute o conceito de intertextualidade no viés trazido pela semiótica. Para o referido autor, os estudiosos de tal ciência não se interessam apenas pelos significados que surgem da linguagem, mas também pelas relações que podem surgir entre a linguagem e as muitas imagens e objetos com as quais interage. Dessa forma, define que intertextualidade:

É uma palavra usada para descrever como obras de vários tipos (livros, pinturas, esculturas, designs, anúncios publicitários, etc.) fazem referência a outras peças, às vezes, de maneira engenhosa (outros livros, pinturas, esculturas, designs, anúncios publicitários, etc). O termo também descreve como os vários significados que essas obras criam são inter-relacionados (p.110).

Neste trabalho, adotaremos o conceito de intertextualidade trazido por Hall (2008). Assim sendo, este estudo tem como objetivo contribuir com a reflexão sobre a importância do entendimento da imagem enquanto texto e não apenas mero recurso para o trabalho com o surdo a fim de desenvolver a leitura e a escrita. Intenta-se também abrir um diálogo para a questão da intertextualidade na educação de surdos e as possibilidades que emergem a partir do trabalho por meio deste viés. Trata-se de uma pesquisa qualitativa e de cunho bibliográfico. De acordo com Gil (1991), “a pesquisa bibliográfica é desenvolvida a partir de material já elaborado, constituído principalmente de livros e artigos científicos" (p. 48). As fontes utilizadas contemplaram basicamente artigos científicos e livros de autores que abordam a questão da intertextualidade e educação de surdos.

\section{Educação de surdos, língua de Sinais e língua portuguesa}




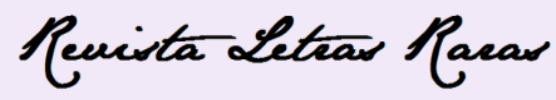

ISSN: 2317-2347 - Vol. 5, Ano 5, № 1 - 2016

Alguns teóricos, tais como Quadros (2007), Skliar (1998), entre outros, que pesquisam sobre a educação de surdos têm apontado que os surdos apreendem o mundo por meio das experiências visuais e têm como direito a aquisição da língua brasileira de sinais como primeira língua. A língua de sinais é de modalidade espaço-visual e é adquirida, como as demais línguas, no contexto comunicativo entre pares. Ocorre que a maioria das crianças surdas tem pais ouvintes e que, portanto, utilizam a língua oral e não a língua de sinais para comunicação com o filho surdo. Isso tem feito com que as crianças surdas adquiram a língua de sinais tardiamente e geralmente quando entram na escola (QUADROS, 2005).

A possibilidade de aquisição tardia da língua de sinais como língua materna pode interferir na aprendizagem da leitura, escrita e processo de letramento (GESUELI, 2006) da mesma forma que o atraso na aquisição da língua oral também pode interferir na aprendizagem da leitura e escrita pelos ouvintes. Porém, em relação ao aluno surdo, soma-se a esta questão o desafio de aprender uma língua de outra modalidade (de uma língua não alfabética que é a língua de sinais para uma língua alfabética que é a língua portuguesa), portanto a aprendizagem da leitura e da escrita por surdos ocorre de forma diferente dos ouvintes.

$\mathrm{Na}$ abordagem educacional bilíngue, acredita-se que a língua de sinais deve ser a primeira língua a ser adquirida pelo surdo num contexto natural e a língua portuguesa deve ser adquirida na modalidade escrita por meio de diferentes estratégias, prioritariamente visuais, como uma segunda língua. Dentro desta perspectiva Gesueli (2006) afirma ser o "processo de aquisição do português escrito pelo aluno surdo uma tarefa altamente complexa: além do trabalho que envolve o ensino da leitura e escrita estamos diante do ensino de uma segunda língua" (p. 39).

Desta forma, a linguagem escrita tem sido pesquisada por estudiosos da área, suscitando questionamentos sobre estratégias e métodos a serem utilizados no processo de ensino e aprendizagem da leitura e da escrita pelos alunos surdos. Os alunos surdos podem aprender a leitura e a escrita num processo de letramento por meio da constituição de sentidos obtidos pela língua de sinais. Ao sinalizar o que é lido ou escrito, a criança surda passará a dar significado à leitura e a escrita e levantará hipóteses de leitura favorecendo a reflexão sobre o texto (QUADROS, 2005).

Fernandes (2006) em seus estudos sobre o processo de aquisição da linguagem escrita por alunos surdos também considera a importância da língua de sinais nesse processo e valoriza o uso de estratégias visuais: 


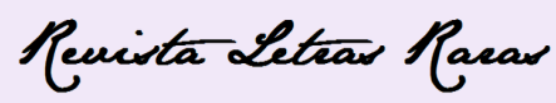

ISSN: 2317-2347 - Vol. 5, Ano 5, № 1 - 2016

[...] sabe-se, sem sombra de dúvida, que é perfeitamente possível que os surdos, mergulhem no mundo da leitura e da escrita por processos visuais de significação que têm na língua de sinais seu principal elemento fundador. Em seu processo de letramento ele passará de uma língua não- alfabética (a língua de sinais) para uma língua alfabética (o português). A condição diferenciada dos surdos que aprendem a ler e a escrever o português sem passar pelo conhecimento fonológico da língua é denominada como a de "leitores não alfabetizados" (p. 6).

O trabalho de letramento com alunos surdos ainda é um desafio para o professor, mas independentemente da surdez, para o processo de ensino e aprendizagem do código gráfico é fundamental a mediação da leitura do texto e a participação do aluno por meio da valorização de seu repertório. Para Fernandes (2006) ler envolve compreender, identificar o significado dos enunciados situar a realidade social, atribuir relações e efeitos de sentido, dentro de um determinado gênero textual, envolvendo questões cognitivas por parte do aluno e metodológicas por parte do professor. Este processo mostra-se complexo para ouvintes nativos da língua, e muito mais complexo para os surdos, em que o português é a sua segunda língua.

Em relação ao trabalho de aquisição da língua de sinais e da língua portuguesa especificamente, verificamos uma tendência ao uso de diferentes gêneros discursivos ou textuais na educação de surdos. Em relação ao conceito de gênero discursivo ou gênero textual, vimos que na literatura há uma discussão envolvendo tais conceitos e que alguns pesquisadores o utilizam como expressões sinônimas e outros até de forma antagônica. Não é foco deste estudo aprofundar essa questão, entretanto, tomaremos como base o conceito de gênero discursivo apresentado na teoria de Bakhtin, à luz de Machado (2013).

Os gêneros discursivos, de acordo com Machado (2013), "incluem toda a sorte de diálogos cotidianos, bem como enunciados da vida pública, institucional, artística, científica e filosófica" (p. 155). Dessa forma, com base na teoria de Bakhtin, os gêneros são divididos entre: discursivos primários (oriundos da comunicação cotidiana) e gêneros discursivos secundários (da comunicação produzida a partir de códigos culturais elaborados).

Trata-se de uma distinção que dimensiona as esferas de uso da linguagem em processo dialógico-interativo. Os gêneros secundários- tais como romances, gêneros jornalísticos, ensaios filosóficos- são formações complexas porque são elaborações da comunicação cultural organizada em sistemas específicos como a ciência, a arte, a política. Isso não quer dizer que são refratários aos gêneros primários: nada impede, portanto, que uma forma do mundo cotidiano possa entrar na esfera da ciência, da arte, da 


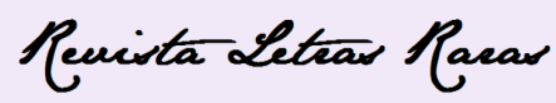

ISSN: 2317-2347 - Vol. 5, Ano 5, № 1 - 2016

filosofia, por exemplo. Em contatos como esses, ambas as esferas se modificam e se complementam (MACHADO, 2013, p. 155).

Com base em diferentes gêneros discursivos, o processo de aquisição de línguas tem sido desenvolvido na educação de surdos. Importante aliado nesse processo é a leitura, seja de textos e ou imagens, assunto a ser discutido a seguir.

\section{Leitura e leitores}

A leitura, vista num sentido mais amplo, não significa meramente uma decodificação mecânica de signos linguísticos, mas sim, para além do texto escrito, é a possibilidade de compreender e valorizar o aprendizado e a experiência vivida (MARTINS, 1982).

$\mathrm{O}$ ato de ler permite a descoberta de características comuns e diferenças entre os indivíduos, grupos sociais, as várias culturas; incentiva tanto a fantasia como a consciência da realidade objetiva, proporcionando elementos para uma postura crítica, apontando alternativas (MARTINS, 1982, p. 29).

Freire (1989) contribui com o entendimento do que seja a leitura quando refere que a leitura de mundo é precedida pela leitura da palavra. Para ele, aprender a ler, a escrever, alfabetizar-se é aprender a ler o mundo e entender seu contexto, constituindo-se como um ato político. Neste sentido, a escola, berço da educação formal, tem um grande papel na formação de leitores e, consequentemente, na formação de escritores por meio de suas práticas pedagógicas.

Entretanto, além das iniciativas promovidas pela escola, é necessário o investimento em políticas públicas, para a implantação de propostas que incentivem a leitura neste e em outros espaços sociais. No Brasil é inegável a necessidade de investimento público para o acesso à leitura e a formação de leitores, porém esta é uma das questões que permeia o processo de desenvolvimento da leitura entre crianças e jovens. Huntz; Christan (2006) entende que além do acesso ao livro, há que se restaurar nos alunos o desejo de ler, a partir de estratégias que relacionam a leitura com o mundo, o tempo e de forma prazerosa.

Mais uma vez, o papel da escola e do professor mostra-se fundamental para o desenvolvimento de bons leitores:

Formar um leitor competente supõe formar alguém que compreende o que lê; que possa aprender a ler também o que não está escrito, identificando elementos implícitos; que estabeleça relações entre o texto que lê os outros textos já lidos; que saiba que vários sentidos podem ser atribuídos a um 


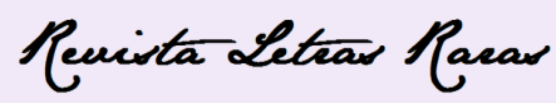

ISSN: 2317-2347 - Vol. 5, Ano 5, № 1 - 2016

texto; que consiga justificar e validar a sua leitura a partir da localização de elementos discursivos (BRASIL, 2000, p. 54).

Butlen (2014) refere que o professor pode contribuir de forma significativa com o processo de aprimoramento da leitura dos alunos por meio do uso de determinadas estratégias, tais como: ativar o conhecimento prévio dos alunos; fazer questionamentos, perguntas sobre o texto; ajudar a estabelecer conexões, inferências, visualização, sumarização e síntese. O referido autor defende a pedagogia da compreensão e interpretação, em que o educador é o mediador entre o texto (imagem e/ou código gráfico) e os saberes de seus alunos. Para isso, ele precisa ensinar estratégias de leitura e apoiar-se na intertextualidade, estabelecendo redes entre os textos a serem lidos.

Assim, criar condição de leitura não implica apenas alfabetizar ou propiciar acesso aos livros. Trata-se, antes, de dialogar com o leitor sobre a sua leitura, isto é, sobre o sentido que ele dá, repito, a algo escrito, um quadro, uma paisagem, a sons, imagens, coisas, ideias, situações reais ou imaginárias (MARTINS, 1982, p. 34).

Com relação ao aluno surdo, o trabalho com leitura não se mostra diferente, pois também envolve um estudo sobre o texto, independentemente do gênero discursivo, por meio da elaboração de hipóteses, do despertar da curiosidade e da busca pelo acerto. Para tanto "levantar hipóteses requer associação com informações anteriores, antecipação de informações sobre o texto, seleção das ideias principais que o texto veicula" (FERNANDES, 2006, p. 15).

Com base na proposta da intertextualidade, no tópico a seguir, trataremos da relação entre imagem e texto e sua consolidação ao longo da história.

\section{A relação entre imagem e o texto: achados históricos}

Para Martins (1982) ler é um ato que se refere tanto a algo escrito quanto a diferentes tipos de expressão do fazer humano e ao considerarmos a possibilidade de leitura de outras formas de expressão, que não apenas o código gráfico, a imagem ganha destaque. Em relação à imagem, Reily (2004) pontua que ela é signo, nunca é a coisa. Além disso, se apresenta como modalidade espaço- visual e é um instrumento importante de representação de "aspectos que se referem ao espaço e que ocorrem na simultaneidade" (p. 30-31). Historicamente podemos perceber o seu uso e presença por meio de registros deixados no campo da arte e outras formas de manifestações iconográficas. 


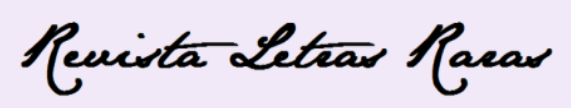

ISSN: 2317-2347 - Vol. 5, Ano 5, № 1 - 2016

Rosart (2012) discorre sobre a história da imagem e sua relação com o texto. Refere que com o advento da escrita, desde os tempos antigos, observa-se a presença do texto com ilustrações e sugere como exemplo o livro dos mortos elaborado pelos egípcios.

\section{Figura 1. Ritos diante da tumba}

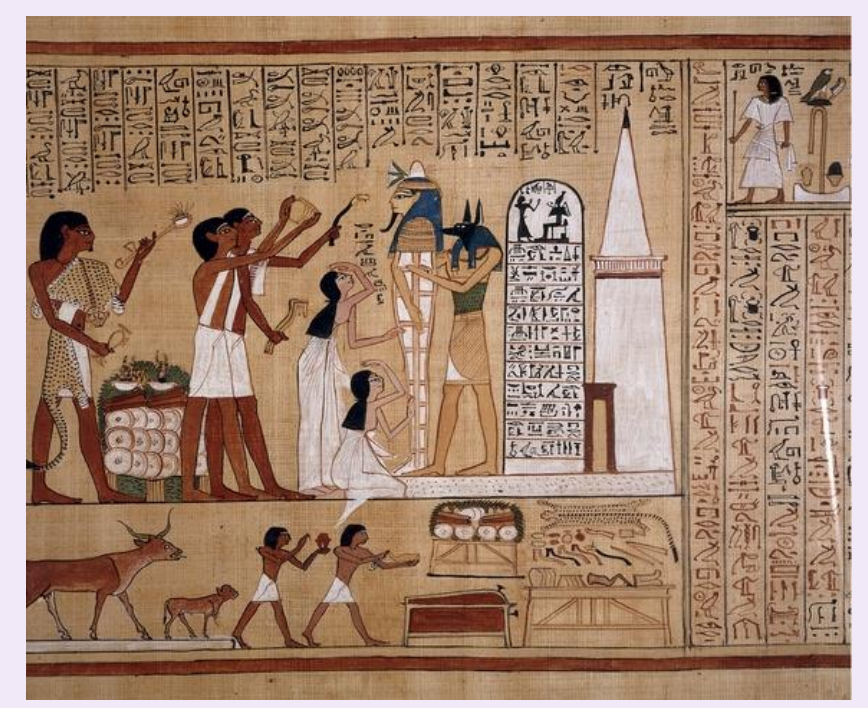

Fonte: Parkinson, 2010.

Na idade média, Reily (2004, p.25) aponta que por volta dos anos 800 d.C, "houve o reconhecimento de que as imagens poderiam servir para os iletrados, que não tinham acesso aos escritos dos antigos pais da igreja, isso numa época em que a maioria da população não sabia ler”. Destaca-se também nesta época o uso de iluminuras ou miniaturas, que deram a imagem um importante papel associado à escrita e enriqueciam os manuscritos produzidos à época.

Apoiada numa tradição que vem da antiguidade, a prática da ilustração dos textos ganhou nesse período uma riquíssima técnica pictórica que envolvia desde a produção das tintas - propriedades dos materiais, a importância da orientação das proteínas de colágeno nas propriedades físicas da folha de pergaminho -, até as características relacionadas às escolas artísticas que contemplavam a arquitetura, a escultura, a pintura e os vitrais das igrejas medievais, como por exemplo, o romântico, o gótico, o mozárabe. A produção cada vez mais frequente, ao longo da Idade Média, da ilustração dos manuscritos, foi possível graças às mudanças no suporte da escrita trazidas pelo uso do códice, formato muito parecido com o livro moderno, que era mais manejável do que o rolo, possibilitando que as iluminuras pudessem acompanhar o texto, auxiliando a sua compreensão. Com os códices os copistas e iluminadores introduziram mudanças substanciais na relação texto/imagem (PARMEGIANE, 2011, n.p). 


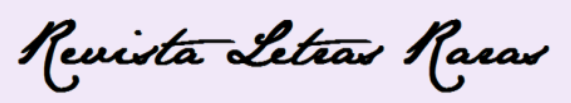

ISSN: 2317-2347 - Vol. 5, Ano 5, № 1 - 2016

Parmegiane (2011) refere que com o uso das iluminuras ficava difícil dissociar o discurso escrito do visual e paulatinamente isso foi se tornando irreversível. As iluminuras foram ganhando cada vez mais destaque e tinham por finalidade ilustrar a bíblia e os comentários aos seus livros, os saltérios, o livro das horas, livros de medicina, bestiários, entre outros. Neste sentido, a imagem foi adquirindo um poder comunicativo próprio, pois além do texto, também abarcava conteúdo também passível de ser lido ao ser utilizada. Como afirma Manguel (2001, p. 21) “as imagens, assim como as histórias, nos informam”.

Figura 2. Ilustração medieval- porco espinho

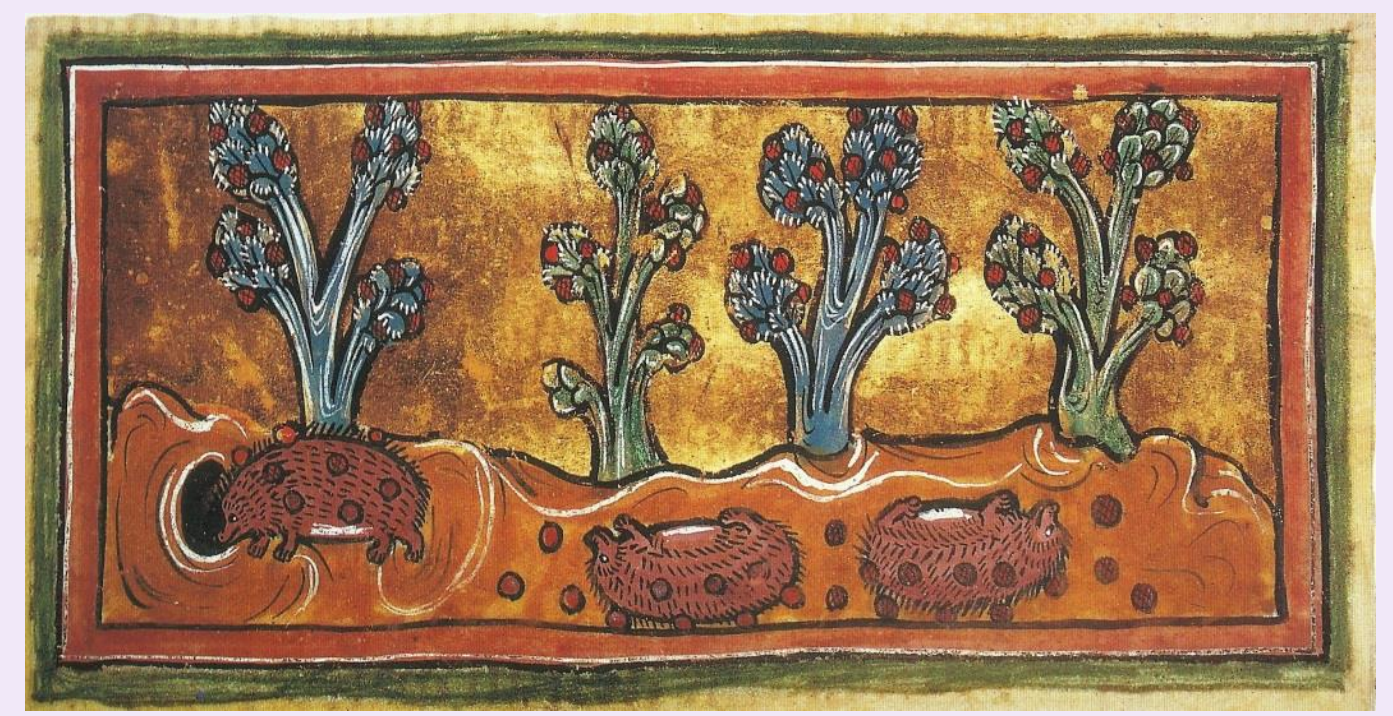

Fonte: Micklethwait, 1999.

Na idade moderna, observa-se uma maior complementaridade entre texto e ilustração, a partir de uma mudança na atitude burguesa que ganha o poder e disponibiliza informações por meio de ilustrações, inclusive para os analfabetos do desenvolvimento industrial (ROSART, 2012).

Na idade contemporânea, especificamente o século XIX, com o surgimento da fotografia, há uma ressignificação em relação à existência e valorização da imagem. Cardoso (2008) aponta que a "segunda metade do século XIX marcou o início de uma nova etapa na valorização cultural, social e econômica das imagens" (p. 61). Entretanto, a relação entre imagem e texto continua existindo, com diferentes funções, destinadas a diferentes grupos de leitores e apresentando-se em variados suportes, entre eles, os livros. Manguel (2001, p, 25) ao discutir o papel da imagem e também do texto refere que: 


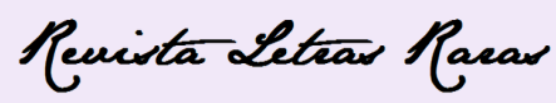

ISSN: 2317-2347 - Vol. 5, Ano 5, № 1 - 2016

Com o decorrer do tempo, podemos ver mais ou menos coisas em uma imagem, sondar mais a fundo e descobrir mais detalhes, associar e combinar outras imagens, emprestar-lhes palavras para contar o que vemos, mas em si mesma, uma imagem existe no espaço que ocupa, independente do tempo que reservamos para contemplá-la.

Nesse jogo de emprestar palavras à imagem, o texto também pode ter um papel fundamental, pois muitas vezes, quando associado a uma imagem, pode desencadear diálogos dos mais variados níveis, a depender do repertório que temos para a interpretação e compreensão de significados. O processo de conferir significados a uma imagem pode ter seu início a partir de seu entrelaçamento com um texto.

Neste sentido, ao longo da história e em diferentes civilizações, Mandel (2006) destaca que existem grandes famílias de escritas, entre elas:

A escrita pública ou monumental, expressão do poder público; a escrita cultural ou livresca, expressão do poder intelectual; a escrita privada ou usual, expressão do poder individual. A estas categorias voluntariamente esquematizadas acrescentam-se hoje em dia a escrita informativa (jornalística), expressão do poder democrático; e a escrita informática (gerencial), expressão do poder tecnológico, esta última é a versão moderna da gerencial manual (p. 65).

O curioso é que a presença da imagem perpassa todos os tipos de escrita mencionados anteriormente. Entretanto, segundo Reily (2004), a escola contemporânea valoriza muito a escrita e a partir do momento que esta passa a ser de domínio do aluno, a imagem que historicamente também acompanha a escrita, vai deixando de ser considerada nas práticas pedagógicas. Embora ambas coexistam na escola, a escrita acaba adquirindo um status superior.

Rosart (2012) entende que a relação entre texto e imagem é muito complexa, apesar de as imagens serem extremamente ricas para o ensino e a aprendizagem, especialmente da leitura. Considerando a imagem e sua potencialidade narrativa, os livros podem ser lidos a partir de suas ilustrações. A autora considera que o texto e as ilustrações têm papeis diferentes e podem apresentar as seguintes funções: função de repetição (texto e ilustração com a mesma mensagem), função de seleção (a ilustração de um aspecto específico do texto), função de revelação (um texto e uma ilustração podem ajudar a dar sentido um ao outro), função completiva (complementaridade - existindo colaboração entre texto e imagem), função de 


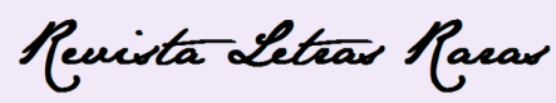

ISSN: 2317-2347 - Vol. 5, Ano 5, № 1 - 2016

contraponto (um texto sintético e uma ilustração detalhada) e função de amplificação (texto ou ilustração podem trazer informações amplas).

Atualmente, os estudantes surdos e ouvintes têm contato com diferentes tipos de imagens em toda parte e por meios variados, e assim sendo, é importante que desde a infância, o aluno aprenda a ler/ compreender uma imagem. A imagem, assim como a escrita, pode ser vista também como texto e não meramente como um recurso para o ensino da leitura. Desta forma, o trabalho de mediação do professor por meio do favorecimento da intertextualidade favorecerá o desenvolvimento de um leitor competente, fundamental para todos os alunos, inclusive para os surdos, que se apropriam do mundo por meio da experiência visual.

\section{A intertextualidade na educação de alunos surdos}

Nas últimas décadas, por conta da abordagem educacional bilíngue e suas implicações, muitos estudos foram realizados acerca dos processos relativos à aquisição de duas línguas no contexto da educação de surdos. Vale destacar que em função dos desafios impostos ao processo de aquisição da língua portuguesa pelos alunos surdos, outras formas de compreensão acerca do fenômeno alfabetização e letramento vêm sendo elucidadas. E neste contexto surgem propostas que abarcam o uso de outros recursos (como a imagem), que combinados ao texto escrito, tentam dar um novo sentido a língua alvo.

Nesse sentido, no contexto da educação de surdos, trataremos da intertextualidade considerando as relações que podem existir entre textos escritos e imagens, no sentido de contribuir com as práticas pedagógicas direcionadas a esse público alvo.

A experiência visual vivida pelo surdo se traduz em todos os tipos de significações, representações e/ou produções intelectuais, por meio do campo intelectual, linguístico, ético, estético, artístico, cognitivo, cultural, entre outros (GESUELI, 2006).

A referida autora ainda reflete sobre a importância da visualidade no processo de letramento de crianças ouvintes e sua extrema relevância no letramento de alunos surdos, que têm contato com o mundo pelas experiências visuais. Corroborando com esta ideia, Reily (2006) aponta que os surdos podem beneficiar-se de um currículo apresentado visualmente e que a imagem poderá ser veículo de mediação sígnica, ou seja, ajudar na compreensão dos significados dos signos presentes no processo de ensino e aprendizagem. Entretanto, a autora nos alerta sobre a importância da escolha e seleção das imagens a serem utilizadas, pois pode veicular conteúdo de alta e baixa qualidade. 


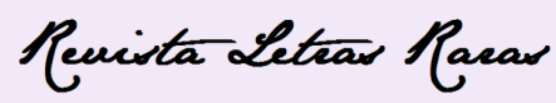

ISSN: 2317-2347 - Vol. 5, Ano 5, № 1 - 2016

Ainda em relação ao processo de letramento e, especificamente, em relação à fase inicial de leitura de uma segunda língua, Fernandes (2006, p. 20) pondera:

[...] as atividades de leitura em segunda língua para aprendizes surdos, principalmente na fase inicial, devem ser contextualizadas em referenciais visuais que lhes permitam uma compreensão prévia do tema implicado, de modo que esse conhecimento seja mobilizado no processo de leitura propriamente dita. A leitura de imagens conduzirá o processo de reflexão e de inferências sobre a leitura de palavra.

A hipótese inicial de leitura para o surdo se realiza pela relação entre as pistas imagéticas e textuais por meio da mediação do professor com a elaboração de questões sobre as imagens e as palavras conhecidas por ele, estimulando essa reflexão (FERNANDES, 2006). A autora considera que principalmente na fase inicial da aprendizagem da leitura e da escrita pelo aluno surdo, os materiais devem ser ricos em imagens e ilustrações, para facilitar a compreensão prévia do tema. A contextualização visual do texto favorecerá a elaboração de hipóteses sobre o que está escrito; a leitura das imagens e a sua relação com suas experiências, despertarão o interesse pelas possíveis mensagens contidas no texto.

Gesueli (2006) afirma que o uso da imagem e sua relação com a linguagem escrita não deve ser vista como uma estratégia proposta apenas no início do processo de letramento do surdo, mas sim que ela deva fazer parte da produção textual deste aluno. A autora então apresenta as seguintes questões:

Sob a ótica da diversidade, poderíamos considerar que os textos dos surdos estivessem permanentemente constituídos de imagens? Seria possível considerar a produção escrita dos surdos como um texto multimodal, atravessado por códigos múltiplos de significação? (GESUELI, 2006, p. 47).

Para o trabalho com letramento de alunos surdos é inegável a importância da utilização da imagem, entendendo-a também como um texto, tanto quanto o texto escrito. Além disso, a relação entre o texto escrito, a imagem e a Libras, por meio da intertextualidade poderão favorecer o processo de aprendizagem do código gráfico bem como a leitura do mundo circundante.

Neste trabalho, a imagem ganha destaque e não é considerada apenas um recurso e sim um objeto de estudo a ser explorado e compreendido em toda sua potencialidade. Nesse sentido, pode- se utilizar também a infratextualidade, que segundo Hall (2008), “descreve o relacionamento interno entre as diferentes partes de um mesmo trabalho" (p. 110), além do 


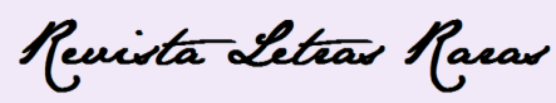

ISSN: 2317-2347 - Vol. 5, Ano 5, № 1 - 2016

diálogo proporcionado pela intersecção entre texto e imagem. Para o mesmo autor "isso pode envolver elementos como a relação entre dois capítulos do mesmo livro, a relação entre duas pessoas retratadas na mesma pintura ou entre dois ou mais objetos que formam uma coleção" (p.110).

Para que este trabalho possa ser realizado, vale destacar a necessidade de formação dos educadores de surdos no que tange ao trabalho relacionado à intertextualidade. Fazer uso de diferentes estratégias requer conhecimento e determinação da factibilidade do processo. Operacionalizar e saber relacionar diferentes linguagens na educação de surdos sugere um investimento e aprofundamento nas áreas da linguística, artes e da semiótica. Para Hall (2008, p. 93), “os estudiosos da semiótica não se interessam somente pelos significados que surgem da linguagem, mas também pelas relações que podem existir entre a linguagem e as várias imagens e objetos com as quais interage"). Nesse sentido, pensamos que no campo do trabalho com a intertextualidade ainda é necessário maior investimento por parte dos educadores de surdos. A busca por caminhos metodológicos mais sólidos e renovados podem conferir às práticas pedagógicas, assentadas na abordagem bilíngue, mais possibilidades e significação, entrelaçando diferentes estratégias. Para tanto, pode-se buscar bases teóricas em outras áreas do conhecimento, tais como a Arte, a Semiótica, entre outras.

\section{Considerações Finais}

Com base nos estudos realizados, pode-se afirmar que a área da educação de surdos passa por um momento de ressignificação no que tange aos processos pedagógicos, especificamente, envolvendo a aquisição da segunda língua (língua portuguesa), na modalidade escrita. Possibilidades outras surgem e fazem pensar sobre a necessidade de intensificação no que se refere à formação de educadores para lidar com os desafios que se apresentam na contemporaneidade no contexto escolar.

Por meio das pesquisas relativas à educação de surdos, percebe-se um avanço no que tange ao uso de estratégias utilizadas em sala de aula e uma atenção maior às possibilidades trazidas pelos recursos visuais, em especial, a imagem neste contexto. Isso se verifica também por meio do investimento em publicações de livros didáticos em Libras e outros materiais de apoio ao processo de ensino e aprendizagem. Entre outros aspectos, estudiosos da área apontam para as possibilidades de trabalho que levem em consideração o uso de imagens nos processos de ensino da língua portuguesa na modalidade escrita e demais áreas do conhecimento. $\mathrm{O}$ ato perceptivo não é passivo e a utilização da imagem em sala de aula com 


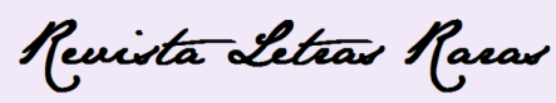

ISSN: 2317-2347 - Vol. 5, Ano 5, № 1 - 2016

alunos surdos é uma forma de provocar a reflexão, além de funcionar como um instrumento que possibilita a aquisição de conhecimentos de diferentes áreas curriculares.

Em nossos estudos vimos que o trabalho com a intertextualidade é uma possibilidade que surge na educação de surdos com mais ênfase no atual momento, considerando a condição desse alunado no que se refere aos processos que envolvem a aprendizagem e a necessidade de recursos visuais para tal. $\mathrm{O}$ uso de textos e imagens e o diálogo entre estes dois suportes de conteúdos tem potencial para favorecer a aquisição das duas línguas em questão na educação de surdos: língua de sinais e língua portuguesa na modalidade escrita, partindo-se do princípio das propostas bilíngues.

A questão que se coloca como premente é como o educador de surdos pode potencializar o aprendizado de seus alunos por meio da intertextualidade e suas implicações? Tendo em vista a constante atualidade da educação de surdos no que se refere aos princípios filosóficos, políticos e também de caráter metodológico, vale destacar a importância da formação inicial e continuada do educador a fim de que possa abarcar os desafios inerentes à educação de surdos e responder a altura os desafios que ainda se fazem presentes relacionados ao processo de ensino e aprendizagem efetiva de tais alunos.

E por derradeiro, frente a todas essas motivações explicitadas neste estudo, fica a máxima expressa por Santaella (2001) “a complexidade do real exige teorias à sua altura”.

\section{Referências}

BRASIL. Decreto $n^{\circ} .5 .626$, de 22 dez. 2005. Regulamenta a Lei ${ }^{\circ} 10.436$, de 24 de abril de 2002, que dispõe sobre a Língua Brasileira de Sinais - Libras, e o art. 18 da Lei $\mathrm{n}^{\circ} 10.098$, de 19 de dezembro de 2000. Diário Oficial da União, Brasília, 23 de dez. 2005.

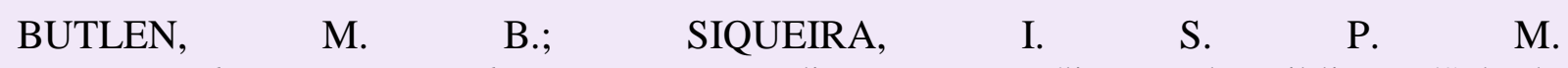
Instâncias de Constituição de Leitores: as Mediações na Família, Escola, Biblioteca/Sala de Leitura em Meios Impressos e Digitais.Universidade de São Paulo. Abr. 2014.

CAVALCANTE, S. M. S. O fenômeno da intertextualidade em uma perspectiva cognitiva. Disponível em: <http://www.letras.ufmg.br/poslin/defesas/1114D.pdf> Acesso em: 5 de ago. 2014.

COPES, R. J.; SAVELLI, E.M. Leitura no Brasil- Programas, Projetos e Campanhas. Revista Leitura Crítica, 2010.

FERNANDES, S. Práticas de Letramentos na educação bilíngue para surdos. Secretaria de estado da educação do Paraná, Superintendência em educação- Departamento de Educação Especial: Curitiba, 2006. 


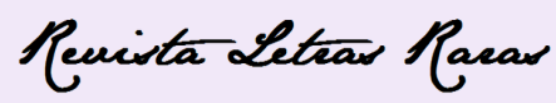

ISSN: 2317-2347 - Vol. 5, Ano 5, № 1 - 2016

FREIRE, P. A importância do ato de ler. São Paulo: Autores Associados/Cortez, 1989.

GESUELI, Zilda Maria. Língua de sinais e aquisição da escrita. In: SILVA, Ivani R. KAUCHAKJE, S., GESUELI, Z. M.. Cidadania, surdez e linguagem: desafios e realidades. São Paulo: Plexus, 2003.

GESUELI, Z. M. A escrita como fenômeno visual nas práticas discursivas de alunos surdos. In: LODI, A. C. B.; HARRISON, K. M. P.; CAMPOS, S. R. L. Leitura e escrita no contexto da diversidade, Porto Alegre: Mediação, 2006.

GIL, A. C. Como elaborar projetos de pesquisa. São Paulo: Atlas, 1991.

GÓES, M. C. R. de. TARTUCI, D. Alunos surdos na escola regular: as experiências de letramento e os rituais da sala de aula. In: LODI, Ana Claudia B., HARRISON, K. M. P., CAMPOS, S. R. L. de. TESKE, O. Letramento e minorias. Porto Alegre: Mediação, 2002.

HALL, S. Isto significa isso. Isso significa aquilo: guia de semiótica para iniciantes. São Paulo: Rosari, 2008.

KARNOPP, L. B. Língua de sinais e língua portuguesa: em busca de um diálogo. In: LODI, A. C. B., et. al. Ottmar. Letramento e minorias. Porto Alegre: Mediação, 2002.

KARNOPP, L. B., PEREIRA, M. C. C. Concepções de leitura e de escrita e educação de surdos. In: LODI, Ana Claudia B. MÉLO, Ana Dorziat B. de, FERNANDES, Eulalia. Letramento, bilinguismo e educação de surdos. Porto Alegre: Mediação, 2012.

LEBEDEFF, T. B. Aprendendo a ler "com outros olhos": relatos de oficinas de letramento visual com professores surdos. Disponível em: <http://www2.ufpel.edu.br/fae/caduc/downloads/n36/08.pdf> Acesso em: 23 de abr. 2014.

LODI, A. C. B. O poder da escrita e a escrita do poder. In: LODI, A.C.B.; HARRISON, K. M. P.; CAMPOS, S. R. L. Leitura e escrita no contexto da diversidade, Porto Alegre: Mediação, 2006.

MACHADO, I. Gêneros discursivos. In: BRAIT, B. (org.). BAKHTIN: conceitos chave. São Paulo: Contexto, 2013.

MANDEL, L. Escritas: espelhos dos homens e das sociedades. São Paulo: Rosari, 2006.

MANGUEL, A. Lendo imagens: uma história de amor e ódio. São Paulo: Companhia das Letras, 2001.

MARTINS, M. H. O que é leitura. Brasiliense: São Paulo, 1982. Parâmetros Curriculares Nacionais: língua portuguesa. Secretaria de Educação Fundamental. 2. ed. Rio de Janeiro: DP\&A, 2000.

MICKLETHWAIT, L. Brincar com Arte. São Paulo: Editora Ática, 1999.

PARKINSON, R. Hunefer and his Book of the Dead. London: The British Museum Press, 2010. 


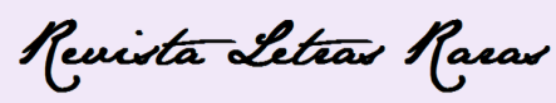

ISSN: 2317-2347 - Vol. 5, Ano 5, № 1 - 2016

PARMEGIANE, R. F. O lugar das iluminuras medievais nas bibliotecas de obras raras. Disponível em: <http://comciencia.scielo.br/scielo.php?script=sci_arttext\&pid=S151976542011000300011\&lng=pt\&nrm=iso > Acesso em: 15 de ago. 2014.

QUADROS, R. M. O Bi do Bilinguismo na educação de surdos. In: Surdez e Bilinguismo. Mediação: Porto Alegre, v.1,2005.

QUADROS, R. M. O tradutor e intérprete de língua brasileira de sinais e língua portuguesa. Secretaria de Educação Especial, Ministério da Educação, 2 ed. Brasília, 2007.

REILY,L. Recursos Pedagógicos: A imagem visual em duas dimensões e a imagem em movimento. Escola Inclusiva- Linguagem e mediação. Campinas: Papirus, 2006.

REILY, L. As imagens: o lúdico e o absurdo no ensino de arte para pré-escolares surdos. In: SILVA, I. R; KAUCHAKJE, S.; GESUELI, Z. M. Cidadania, surdez e linguagem: desafios de realidades. São Paulo: Plexus Editora, 2003.

REILY, L. Escola inclusiva: linguagem e mediação. Campinas, SP: Papirus, 2004.

ROSA, E. F., LUCHI, Marcos. Semiótica imagética: a importância da imagem na aprendizagem. Disponível em: http://www.celsul.org.br/Encontros/09/artigos/Emiliana\%20Rosa.pdf. Acesso em: 26 de nov. de 2013.

ROSART, P. Texte / graphiques rapport sur la jeunesse d'un album, il perturbe la compréhension d'un élève du cycle 1?, Institut universitaire de formation desenseignants, Université d'Artois, France 2012, disponible à l'adresse <http://dumas.ccsd.cnrs.fr/docs/00/75/04/03/PDF/rosart_pauline.pdf>Consulté Juin 2012.

RUNTZ-CHRISTA N, E. La littérature : les enfants doivent entrer dans la salle de classe? Dossier: "Littérature pour enfants, une nouvelle discipline scolaire? » Sommaire, $\mathrm{n}{ }^{\circ} 462$, avril 2008 - Édition au format PDF, disponível em : <http://www.cahiers-pedagogiques.com/Lalitterature-jeunesse-doit-elle-entrer-dans-les-salles-de-classe> consultéle 4 Juin 2013.

SOFIATO, C. G.; REILY, L. Dicionários e manuais de língua de sinais: análise crítica das imagens. In: LACERDA, C. B.F. de; SANTOS, L. F. Tenho um aluno surdo, e agora? Introdução à Libras e educação de surdos. São Carlos: EDUFSCAR, 2013.

TAVEIRA, C. C.; ROSADO, L. A. S. Por uma compreensão do letramento visual e seus suportes: articulando pesquisas sobre letramento, matrizes de linguagem e artefatos surdos. Espaço, Rio de Janeiro, n.39, jan/jun. 2013.

Recebido em: 22/03/2016

Aceito em: 30/06/2016 